\title{
A NEGOTIATED SOLUTION FOR THE JORDAN BASIN
}

\author{
M. Atwi, J. Sánchez Chóliz \\ Majed Atwi, Department of Economics Analysis, Faculty of Economics and Business \\ Administration, University of Zaragoza, Spain \\ Julio Sánchez Chóliz, Department of Economics Analysis, Faculty of Economics and \\ Business Administration, University of Zaragoza, Spain \\ E-mail matwi@unizar.es
}

\begin{abstract}
The use of water in the Jordan Basin has been a key factor in the conflict between Israel and the Palestinians, and between Israel and its neighbors. Efficient water use requires cooperation rather than confrontation, however. In this paper, we explore possible ways of sharing water through a negotiation game with two players -Arabs and Israelis. We determine the gross margins and estimate a set of optimum Pareto allocations, as well as identifying a range of negotiated solutions: regular and general Nash, Kalai-Smorodinsky, Johnston Plan.

In order to obtain and interpret the different solutions to the game, we need the utility functions for each player, possible negotiating alternatives and a set of criteria allowing the evaluation of results.

The percentage of water used in agriculture is very similar for both players. In view of this, and of the predominance of agricultural water use, as well as certain weaknesses in the data available, we shall use agricultural returns as the basis for the utility functions. Defining the possible negotiating alternatives between the Arabs and the Israelis, which is to say the set of efficient Pareto alternatives. The negotiation set will, therefore, be the set of efficient points that do not result in utilities below the break-off point for both players. We assume that these points are associated with a greater or lesser transfer of the water used between the agents, since an increase in the available water can hardly be supposed given the ecological problems facing the Dead Sea. For reasons of realism, we shall moreover suppose that transfers are possible only in one direction from Israel to the Arabs. We also assume that the Israelis will always transfer the water providing the lowest return, while the water received will be used by the Arabs to expand their agriculture without changing crop patterns. This conjecture seems reasonable, given that the share of herbaceous crops farmed by the Arabs is relatively small, and that it is not easy to raise a product's market share quickly.

The "fair water sharing" is a necessary principle for any water allocation, but it is one of the most difficult to define, given the multitude of variables that should be taken into account. We have used the fair factors inspired
\end{abstract}


in the Helsinki Rules developed by the International Law Association in relation to the fair use of water, as well as the criteria we have used to apply them in the present case.

As a first step, we assume that the break-off point for both players is the unavailability of water, therefore representing zero utility. On this assumption, we find four possible solutions, all based on the negotiating set and all revealing. Two are Nash negotiating solutions with and without lateral payments. The third is the RaiffaKalai-Smorodinsky solution, and the fourth is the proposal made in the Johnston Plan.

Under these conditions, the regular Nash solution without lateral payments is that maximizes the product of gains (utility less utility at the break-off level) for each player. Comparing the solution of this problem of maximization to the current status quo, Israel would lose around $€ 130$ million, and the Arabs would increase their income by some $€ 336$ million, raising overall utility by $20 \%$. The transfer of water to the Arabs would be in the order of $536.26 \mathrm{hm}^{3}$, but the water actually used would be the same.

Assuming, in the context of negotiation games, that both Israel and the Arabs, the two players, can make lateral payments (i.e. mutual transfers of income), it is clear that the negotiating set will differ from that considered in the preceding case. Meanwhile, only solutions in which both players receive non-negative amounts and that add up in total to the maximum obtainable income will be considered negotiable. The maximum level of joint utility is greater than the obtained in the previous Nash solution. This point is not, however, the Nash solution. By symmetry alone, it can be seen the Nash solution with lateral payments.

The Raiffa-Kalai-Smorodinsky solution represents an alternative to the Nash solution. This solution for the two players is neither more nor less than the intersection between the negotiating set and the line joining the breakoff point and an ideal point which is the maximum utilities that can be achieved by the players within the negotiating set. The joint income produced is close to the amount obtained at the two previous calculated Nash negotiating solutions with and without lateral payments and it results in a gain of approximately $20 \%$ in income for the Arabs compared to the initial status quo.

We have also considered the solution proposed in the Johnston Plan (1953-1955), as well as those associated with various fair distribution criteria. If the water proportions proposed in the Johnston Plan for the Jordan Basin are applied to the flows in our game, the result obtained is the point in the negotiating set represented by 
the Johnston Plan. This is surprisingly close, indeed practically identical, to the Nash solution, proving the validity of the proposal made in the Johnston Plan, which 50 years on could still be rationally defended.

Up to this point, we have considered regular Nash negotiating solutions in which both players have the same negotiating power. To put this another way, the game treated both players symmetrically. In reality, however, players usually have different levels of negotiating power, and this assumption may be an appropriate avenue to approach the situation considered here, which is the sharing of water between Israel and the Arabs. For reasons of brevity, we shall look only at general solutions with break-off points at the origin and certain values of negotiating power. As might have been expected, the players increase their gains where they have greater negotiating power.

Nevertheless, the overall utility of the four solutions is very similar, and all of them would result in an increase of approximately $20 \%$ compared to the current status quo. All of this suggests that the 1955 Johnston Plan could be revisited as a starting point for present-day negotiations. However, it would be required some adjustment to make room for modern approaches to integrated, sustainable management, but the Plan proposals appear to provide an acceptable combination of the possible, the technical and the socially desirable. Meanwhile, theoretical fairness criteria, which are more favorable to the Arabs than the Johnston Plan, are not actually better in technical terms and could in any case only be achieved if the Arabs' negotiating position were much stronger than the Israelis'. At the same time, the status quo is not technically optimum and is only sustainable given a much stronger bargaining position on the part of the Israelis.

Finally, it should not be forgotten, however, that this proposed theoretical approximation solution to such a possible agreement using a simple Nash-type negotiation game, is merely an exercise, and that any on-theground solution would involve many other factors. 


\section{BIBLIOGRAPHY}

Baer, G. et al. (2002) The Lowest Place on Earth is Subsiding-An InSAR (Interfermetric Synthetic Aperture Radar) Perspective. Geological Society of America Bulletin, Vol. 114, $\mathrm{N}^{\mathrm{o}} .1$, pp. $12-23$.

Elmusa, S. (1998) Toward a Unified Management Regime in the Jordan Basin: The Johnston Plan Revisited, in: Jane Coppock and Joseph A. Miller, series (Eds.) Transformations of Middle Eastern Natural Environments: Legacies and Lessons. Bulletin Series, Number 103, Council on Middle East Studies, Yale Center for International and Area Studies, and the Yale School of Forestry and Environmental Studies (New Haven, Yale University Press), pp. 498.

Kalai, E. and Smorodinsky, M. (1975) Other Solutions to Nash's Bargaining Problem. Econometrica, 43(3): 513-518.

Mimi, Z. and Sawalhi, B. (2003) A Decision Tool for Allocating the Waters of the Jordan River Basin between all Riparian Parties, Water Resources Management, 17: 447-461.

Nash, J. F. (1953) Two Person Cooperative Games, Econometrica, 21(1):128-140.

Raiffa, H. (1953) Arbitration Schemes for Generalized Two-Person Games, in: H.W. Kuhn and A.W. Tucker, (Eds.) Contributions to the Theory of Games II (Princeton, University Press), pp. 361-387.

Wolf, A. (1999) Criteria for Equitable Allocations: The Heart of International Water Conflict, Natural Resources Forum, 23(1): 3-30. 